\title{
Fuzzy Logic Based Controller Effective Energy Management OfComposite Energy Storage System Involving Battery AndUltracapacitor inMicrogrid
}

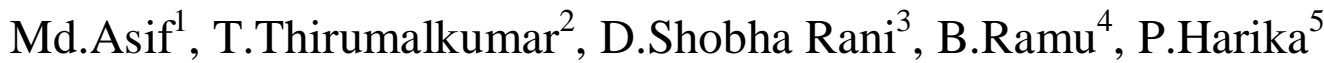 \\ 1, 2, 3, 4, 5 (EEE, Vardhaman College of Engineering (Autonomous), JNTU, Hyderabad, India)
}

\begin{abstract}
In present world usage of fossil fuels are increasing, in order to decreasethem the alternate option isRenewable-energy-basedmicrogrids, they are a better wayof utilizing renewable power and reduce the usage of fossil fuels. Usage of energy storage becomesmandatory when such microgridsare used to supply quality power to the loads. Microgrids have twomodes of operation, namely, grid-connected and islanding modes.During islanding mode, the main responsibility of the storage isto perform energy balance. During gridconnected mode, the goalis to prevent transmission of the renewable source intermittency and load fluctuations to the grid. Energy storage of a single typecannot perform all these jobs efficiently in a renewable poweredmicrogrid. The alternating nature of renewable energy sourceslike photovoltaic $(P V)$ demands usage of storage with high energydensity. At the same time, quick fluctuation of load demandsstorage with high power density. This paper shows a compositeenergy storage system (CESS) that contains both high energy densitystorage battery and high power density storage ultracapacitorto meet the aforesaid requirements. By using DAB powerconverter configuration and the energy management scheme canactively distribute the power demand among the different energystorages. Using fuzzy logic controller
\end{abstract}

Keywords: Bidirectional converter, energy management,energy storage, interleaved modulation, modular design andmicro grid.

\section{Introduction}

Due to the intermittent nature of renewable energy sourcesand the incessant variations of the load, storage (e.g.,battery, ultracapacitor, flywheel etc.) is usually needed in a renewablepowered microgrid. The renewable output power profileand the load profile are two important factors in deciding thecapacity and type of the energy storage components. The variationin output power from a utility-scale PV system is presented.In fig [1],

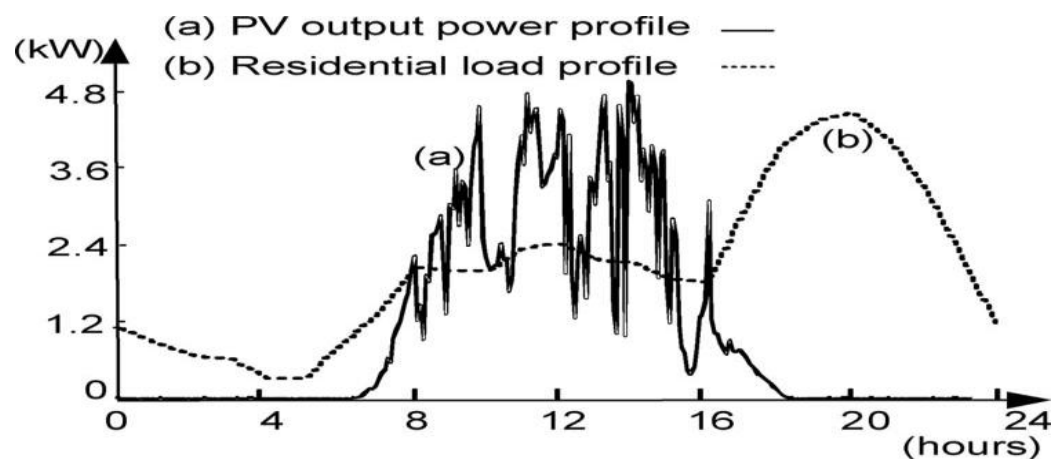

Fig. 1. Typical 24-h (a) PV output power and (b) residential load profile

From the fig 1 we can observe that variations in the pv output power profile comparing to residential load profile ,inorder to compensate the pv output power with residential load profile we requireComposite energy storage system (CESS) which includes battery and ultracapacitor, If we use only ultracapacitor, then it has tobe oversized for storing large amount of energy to take care ofthe intermittency of the renewable sources and loads.Hence, use of a Composite energy storage system (CESS)encompassing both high power density and high energy densitystorage units is practically necessary. Now, the selection ofthe type of storage is also crucial.

For energy storage in the highpower range for standard power systems, the most suitable oneswould be pumped hydro storage, compressed air storage, etc. 


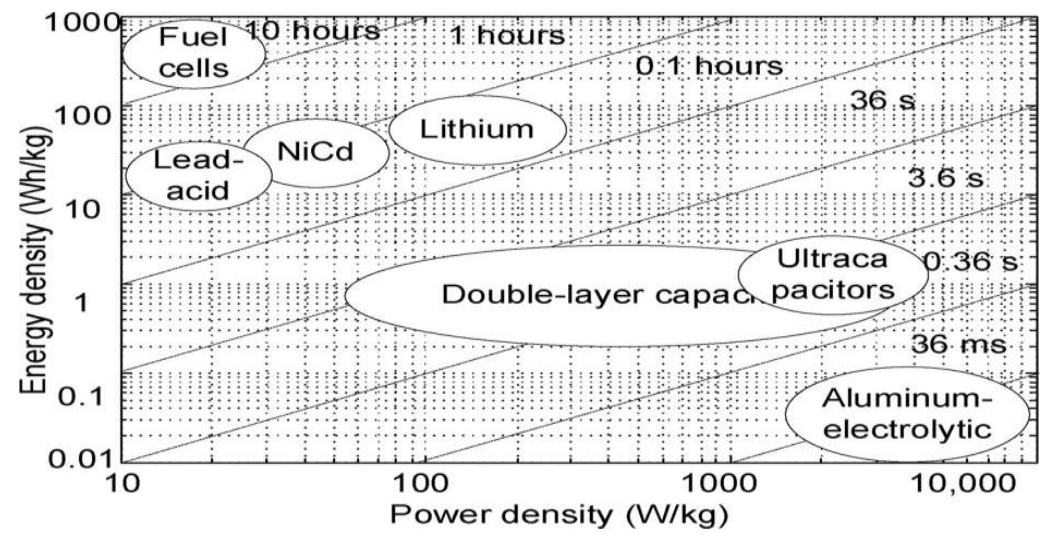

Fig. 2.Ragone chart showing the power density and energy density of different Storages.

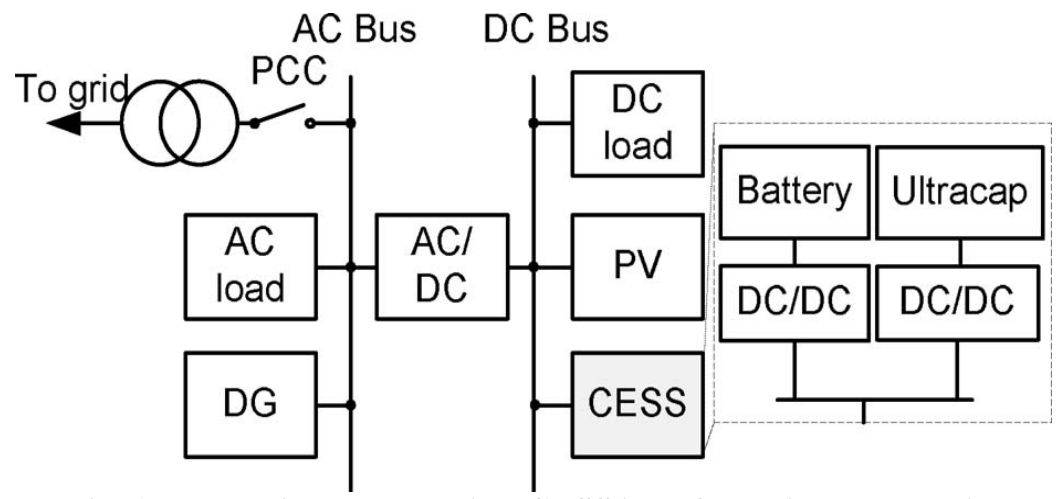

Fig. 3. Block diagram showing CESS interface with the dc grid.

However, for microgrids, where power levels are in the rangeof a few megawatts, battery, ultracapacitor, and flywheel arethe more suitable options. Battery and ultracapacitor are consideredas high energy density storage and high power densitystorage, respectively, and their combination is a very promisingoption to realize the CESS system. Fig 3 shown thatultracapacitor-battery hybrid energy storage performs better

Than battery-alone energy storage for a stand-alone PV system.. fig 4 shown that battery-ultracapacitor hybrid storagehas the virtues of both high energy density and high power

Density, and also, such system increases battery life. .fig 5 analytically proved that batteryultracapacitor hybridachieves power and life extension of battery. This paper alsoexploits the potential of battery and ultracapacitor as a CESS, as shown in Fig. 3.Bidirectional dc-dc converters are required to interface thebattery banks and the ultracapacitor to the dc link for controllingthe power flow. The basic requirement from the dc-dcconverter is that the user should be able to dynamically allocate the load current demand between the battery and the ultracapacitor.Different power converter structures are proposed in theliterature for interfacing battery and ultracapacitor to the de link.Fig 6 proposed that an ultracapacitor with aboost chopper can be connected to the terminals of the battery,and battery current can be indirectly controlled by controllingthe ultracapacitor current. fig 7 proposed a technique,where ultracapacitor is connected to the battery with reducedpower device rating.

The salient features of the proposed CESSsystem are:

1) dynamic allocation of steady power demands andtransient power demands to the batteries and ultracapacitor, respectively;

2) flexible distribution of power flowamong differentbatteries without disturbing the normal operation and online battery

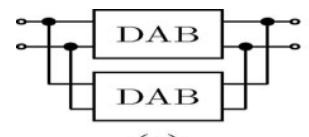

(a)

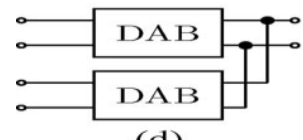

(d)

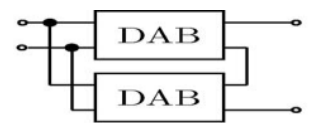

(b)

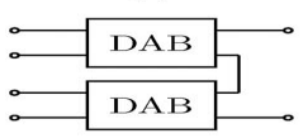

(e)

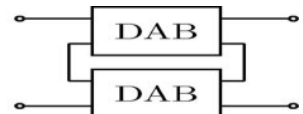

(c)

Fig. 4.Few possible configurations of module-based converter. 
(a) IPOP. (b) IPOS. (c) ISOS. (d) Modified version of IPOP.

(e) Modified version of IPOS.replacement;

(3) ultracapacitor charging-discharging withoutdisturbing the normal operation; and

(4) flexibility to upgradethe power rating or energy rating of the CESS systemindependently.

Incorporation of these features has been possiblebecause of the proposed unique modular power converterstructure.

\section{Usage of Dab Converters}

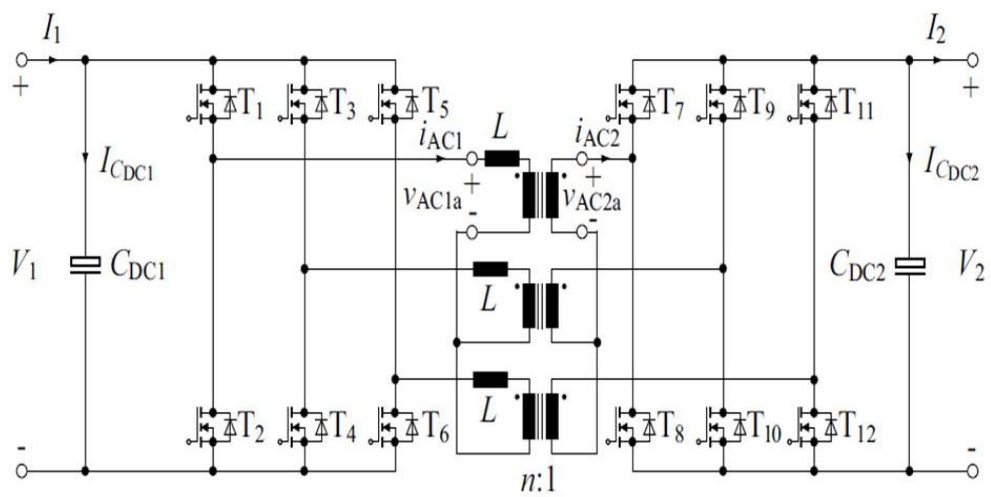

Three-phase Dual Active Bridge (DAB) converter topology.

As mentioned earlier, module-based design is the best approachto satisfy all the requirements of energy storage andload. The configurations of module-based converter are shownin Fig. 4. Input parallel output parallel (IPOP) configuration, asshown in Fig. 4(a), shares the input and output current in modules.By controlling the input current in each of the converters, the power flowin each can be controlled .Fig. 4(d) is derivedfrom Fig.

4(a) to interface multiple sources. This is also a commontopology in connecting multiple sources [18]. Input paralleloutput series (IPOS) topology presented in Fig. 4(b) shares thecurrent in the parallel side, while achieves high voltage in theseries side. Therefore, it is suitable for applications, where energystorage and load have large voltage difference. Fig. 4(e)is derived from Fig. 4(b) to interface multiple sources. Input

Series output series (ISOS) configuration of Fig. 4(c) sharesvoltage both in input and output side. It is favorable for highinput and output voltage application. This connection is especiallyuseful when power increases to megawatt level, sincehigher voltage can help to reduce the magnitude of current toachieve lower loss .In all the aforementioned schemes, the basic power converter module used is the DAB. The module-based converter design approachesnot only can match the different source and load requirements, but also share the power in each module, and thus help to reducethe switch stress. Table. I lists the comparison of switchstress and transformer turns ratio in IPOP, IPOS, and ISOS

TABLE I

Comparison of Device Stress under Same Output Power

\begin{tabular}{l|l|l|l}
\hline & $\begin{array}{l}\text { IPOP } \\
\text { (p.u.) }\end{array}$ & $\begin{array}{l}\text { IPOS } \\
\text { (p.u.) }\end{array}$ & $\begin{array}{l}\text { ISOS } \\
\text { (p.u.) }\end{array}$ \\
\hline Primary & & $1 / n$ & \\
Switch Current Rating & $1 / n$ & 1 \\
Switch Voltage Rating & 1 & 1 & $1 / n$ \\
\hline $\begin{array}{l}\text { Secondary } \\
\text { Switch Current Rating }\end{array}$ & $1 / n$ & 1 & 1 \\
Switch Voltage Rating & 1 & $1 / n$ & $1 / n$ \\
\hline Turns ratio & 1 & $1 / n$ & 1
\end{tabular}

With single $\mathrm{DAB}$ converter, respectively. Base values are chosenaccording to single DAB rating when same power and sameinput/output voltage are used. From Table. I, we can clearly seethe advantages of different topologies in switch rating selection.For example, the current rating for primary-side switches andvoltage rating for the secondary-side switches are reduced tol/n p.u. (as shaded rows) when $\mathrm{n}$ modules are connected 
underIPOS structure.This modular design approach is followed in realizing thepower converter structure in the proposed CESS system.

\section{Proposed Power Converter Structure}

The ultracapacitorneeds to supply or absorb high current for a shortduration of time. Considering these requirements, the modularpower converter structure adopted for interfacing battery andultracapacitor to the dc bus is shown in Fig. 5. The added advantageof such modular structure is that if $\mathrm{n}$ parallel DABbranches are used, then by applying the interleaving scheme,the input-current and output-voltage ripple frequency can be increasedby a factor of $\mathrm{n}$ and ripple magnitude can be reducedto less than $1 / \mathrm{n}$ compared to single DAB. At this point, it is importantto explore the reconfigurability of the proposed modularpower converter structure of Fig. 5 .

If the energy density of theCESS needs to be increased, then we can add parallel branchesto the battery side, as shown in Fig. 5. High energy density maybe required, if the microgrid is powered from only renewable sources. Similarway, more ultracapacitor branches can be addedto increase the power density of CESS. High power density maybe required for CESS used in traction application, where highburst of power is supplied or absorbed during acceleration orbraking, respectively. Moreover, the power converter structurecan be easily reconfigured to achieve different dc-link voltagelevels, as shown in Fig. 6

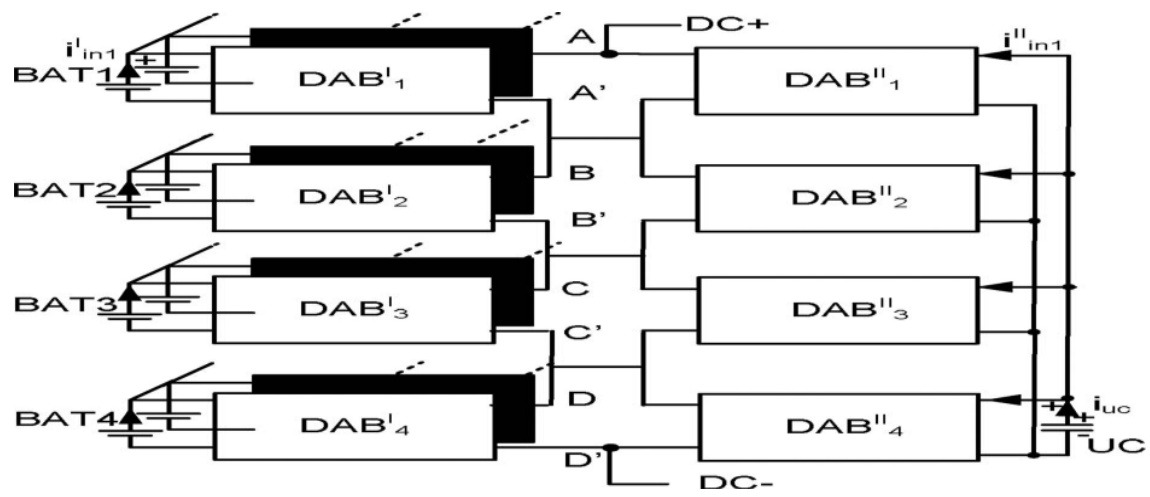

Fig. 5. Topology of the proposed interleaved DAB-based CESS.
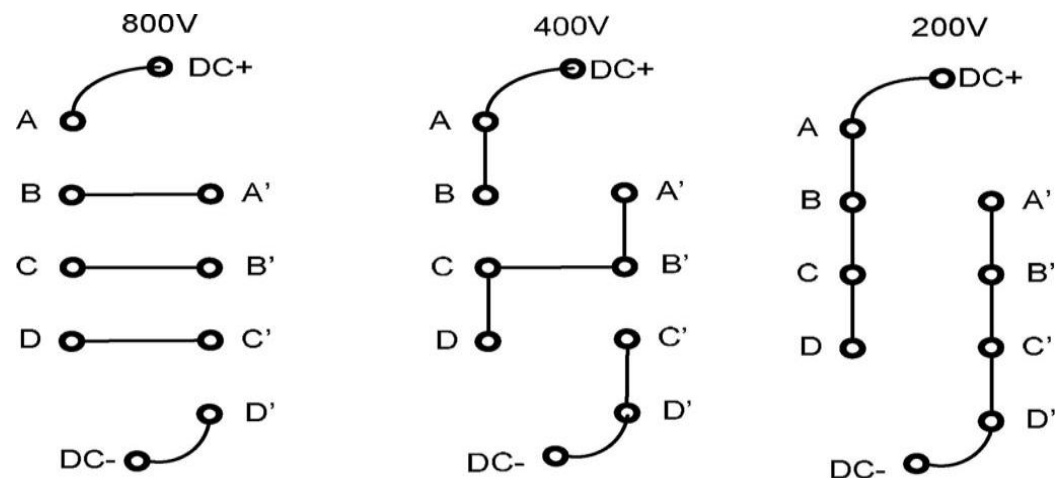

Fig. 6. Reconfiguration of the power converter structure to satisfy differentdc-link voltage requirements.

\section{Proposed Control Strategy Of Dabs For Energymanagement Of The Cess System}

The control scheme for energy management of this CESS systemis shown in Fig. 7. The symbols used to represent differentvariables are defined in the Appendix. DAB converter is selected as abasic cell in our application. The power transfer is achievedby phase shifting the voltage across the primary and secondarysides of the high-frequency transformer. The detailed operatingprinciples of DAB is explained in . Every DAB has acurrent-control loop associated with it. The output of the currentcontroller generates the phase-shift information between the inputand output bridges of the DAB module. The task of theenergy management block of CESS is to generate appropriatecurrent reference for each DAB module. Forthe analysis, the direction of current flowing out of battery andultracapacitor is taken as positive, as shown in Fig. 5. 


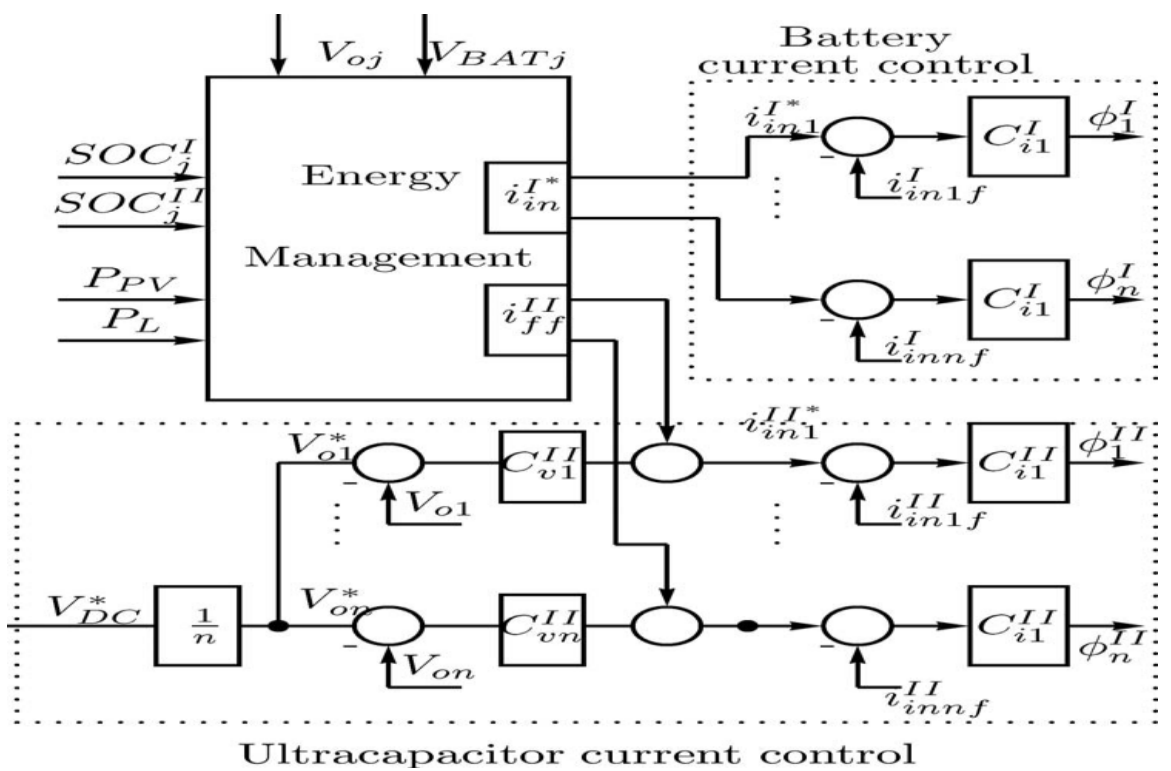

Fig. 7. Control block diagram for the IPOS interleaved DAB converter.

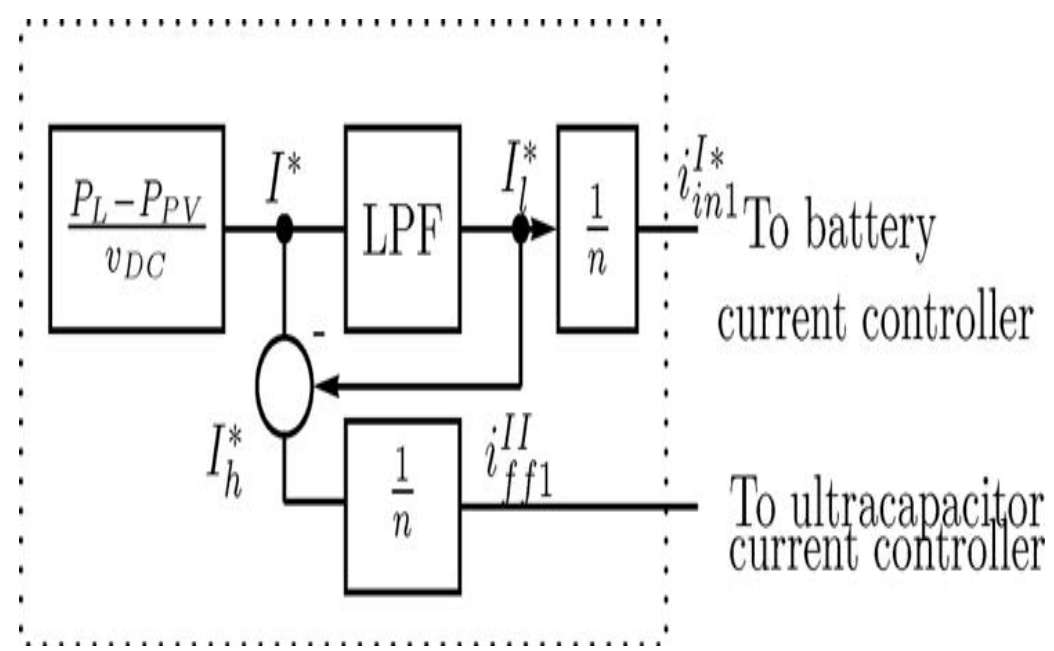

Fig. 8.Energy management strategy for case $I$.

\section{Output Simulation Result}

Simulation result of Based On Fuzzy Logic Controller Effective Energy Management In Composite Energy Storage System Involving Battery And Ultracapacitor In Microgrid Applications

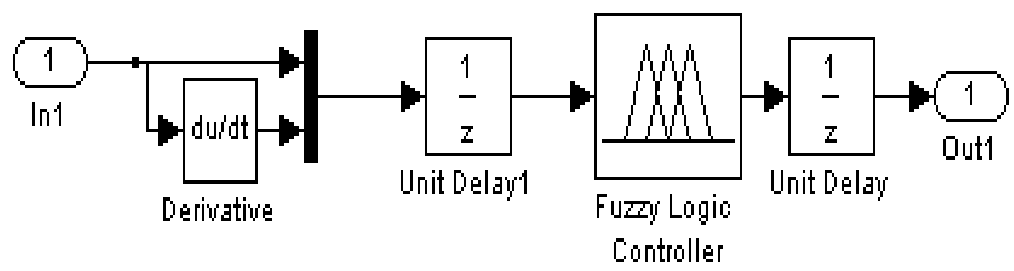




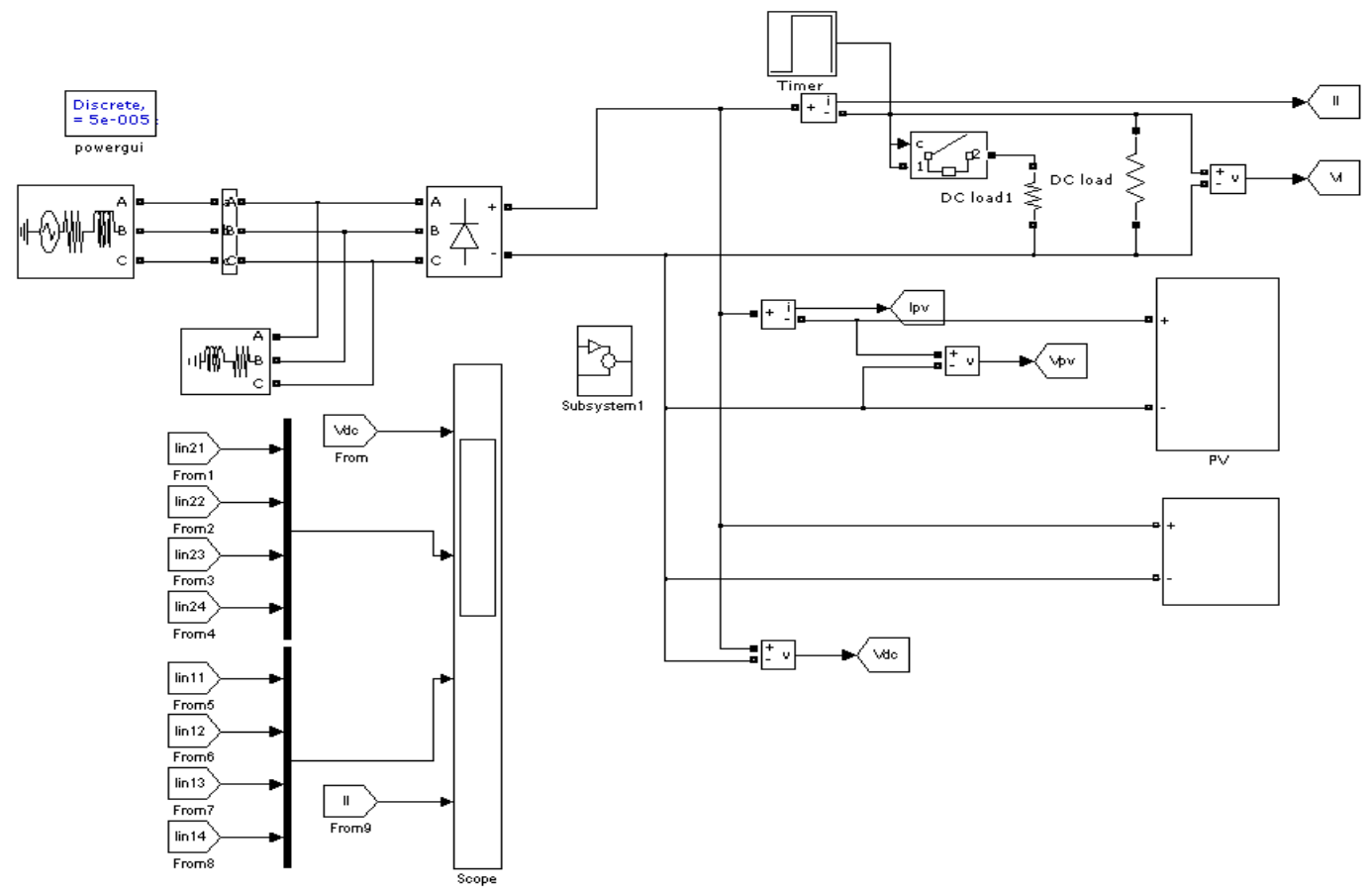

A. Case I: Dynamic Allocation of Power Demand to Batteriesand Ultracapacitor

One objective of the energy management system is to allocatesteady power demand to the batteries and transient powerdemand to the ultracapacitor. We can think of a specific exampleof a dc grid, where PV generator and load are connectedalong with the CESS system. The block diagram of the overallcontrol scheme is shown in Fig. 7, and the current referencegeneration strategy for this specific case is shown in Fig. 8. The total current demand from the CESS system is calculateddepending on the difference between energy source power andload power. Here, the current demand can be positive or negativedepending on the difference. Then, this current reference ispassed through a low-pass filter (LPF) to get the low-frequencycomponent of the current demand. This low-frequency componentI* 1 is used to generate the total current reference for thebattery interfacing power converters. As there are n parallelDAB branches, the current reference for each branch would beI* $1 / \mathrm{n}$. In this case, it is assumed that, all the batteries are at thesame state of charge (SOC). For controlling the DABs interfacingthe ultracapacitor, a cascaded control scheme using innercurrent-control loop and outer voltage-control loop is realized.The high-frequency component of the current demand from theCESS system is added as feedforward term at the output ofthe voltage controllers. The value of this feedforward term foreach $\mathrm{DAB}$ branch is equivalent to $\mathrm{I} * \mathrm{~h} / \mathrm{n}$. To verify this controlstrategy, simulation is carried out in SIMPLORER software.

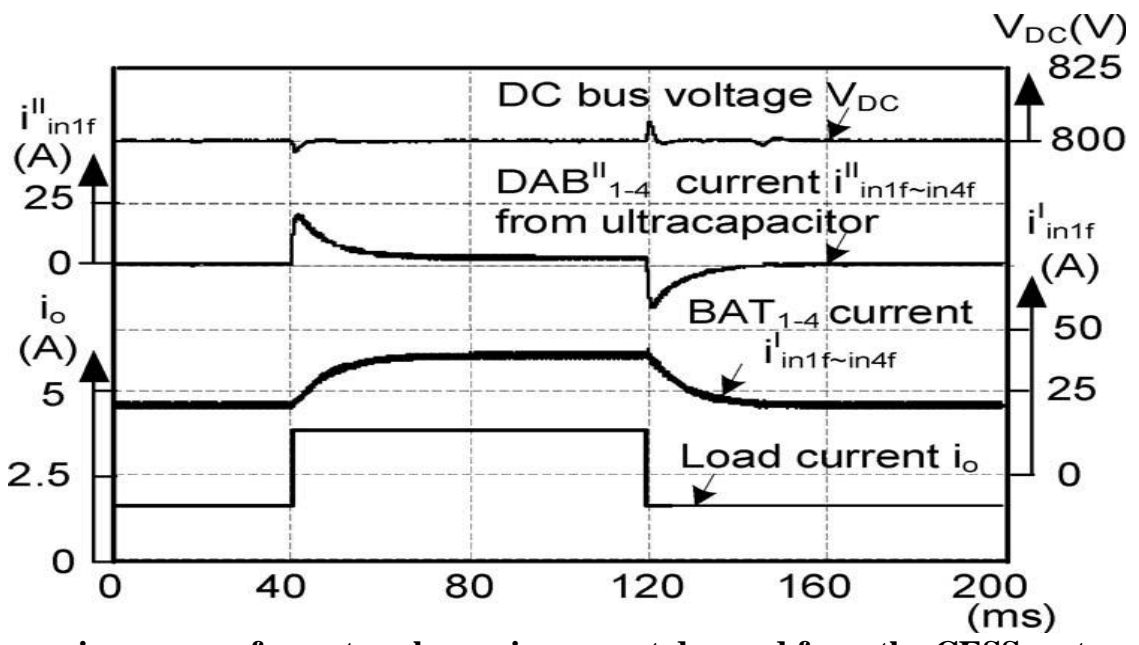

Fig. 9. Dynamic response for a step change in current demand from the CESS system (Case I). 


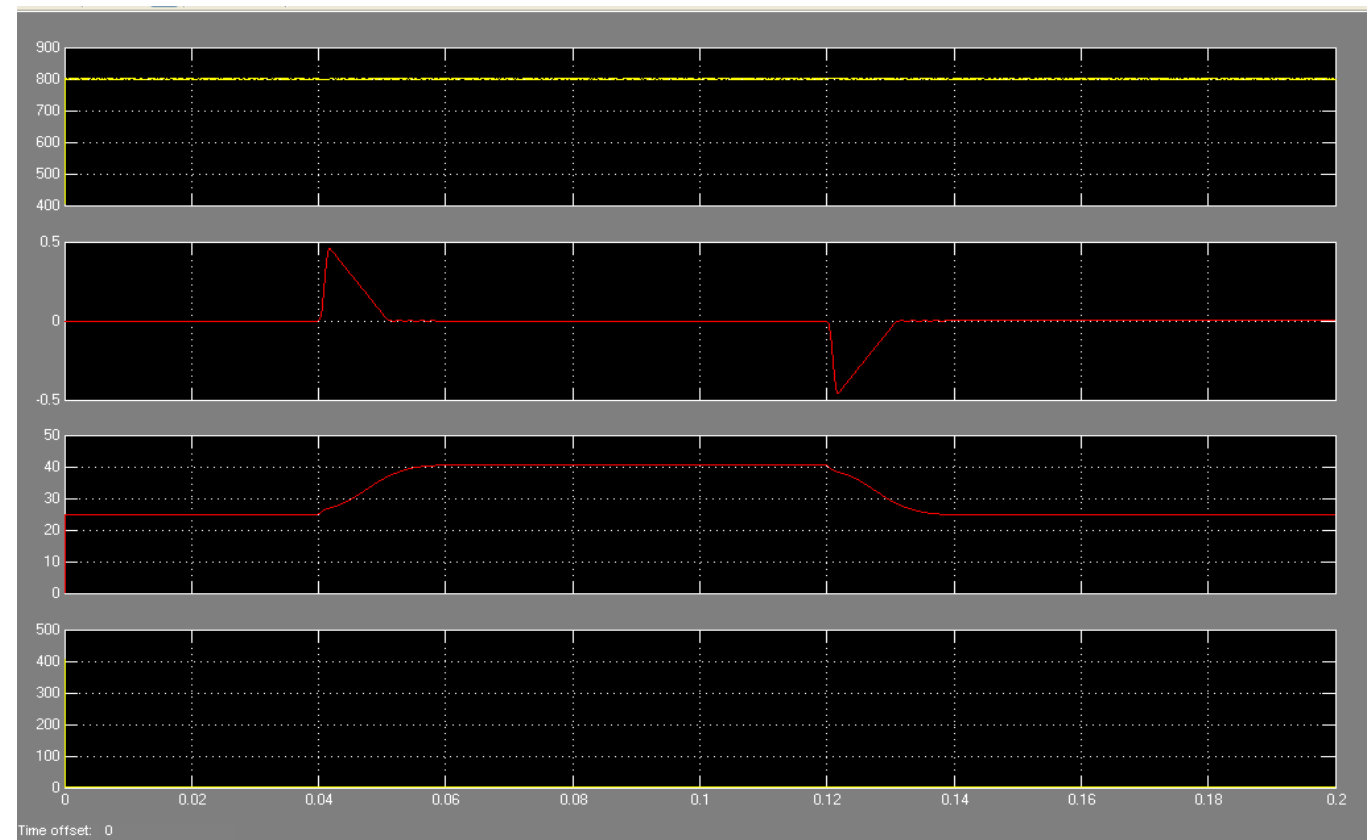

Fig. 9.1. Output simulation result of Case I: Dynamic Allocation of Power Demand to Batteries andUltracapacitor

Four parallel branches are considered. Each branch is rated for $1.2 \mathrm{~kW}$. In order to justify the scheme in a practical scenario, upto $20 \%$ variation in leakage inductance and output capacitanceare considered. Fig. 9 shows the dynamic response of the dc-linkvoltage and the average converter input currents for step variation in current demand from the CESS system. In practice, asudden variation in current demand can occur for switching ONor switching OFF some particular load or for sudden change insolar insolation because of passing clouds. At $\mathrm{t}=40 \mathrm{~ms}$, thereis a step increase in the load current. It is evident from Fig. 9 thatultracapacitorinterfacing converter currents $\operatorname{Iiiin}(1 \mathrm{f}-4 \mathrm{f})$ compensatesfor the sudden current dynamics, and the battery currents iIin(1f-4f ) slowly increases to cater to the steady load demand.The time constant of the LPF shown in Fig. 8 is kept as only50 ms to show the operating principle. In practice, this cutofffrequency has to be set depending on the relative capacity ofthe battery and ultracapacitor. Similar response can be seen fora step decrease in load current at $\mathrm{t}=120 \mathrm{~ms}$.

\section{B. Case II: Energy Management of the Batteries}

In an ideal case, all the batteries can source or sink same current.But in practice, different batteries will be in different statesof charge and their equalization is required. In the example ofthe earlier section, the current reference for all the batteries areset equal as $\mathrm{I} * 1 / \mathrm{n}$. However, the energy management scheme can actually allocate different current references for differentbatteries depending on their states of charge. Fig. 10(a) showsthat if same current is drawn from all the four batteries withonly one of them having higher SOC, then batteries with lowerSOC can go into deep discharge. Hence, if we put a deep dischargelimit, then the energy stored in the battery with higherSOC cannot be fully utilized. In fact, this result also indirectlyexplains that, if many batteries are connected in series to forma high-voltage dc-link, then volumetric efficiency of the battery bank will be decided by the battery with lowest SOC, resultingin reduced energy density. However, if current drawn from individualbatteries is proportional to their individual SOCs, thenall the batteries will hit the deep discharge limit together andtheir energy can be fully utilized as shown in Fig. 10(b). In thiscase, the battery with higher SOC supplies more current till allthe batteries reach same SOC. The authors in [19] and [20] ex-

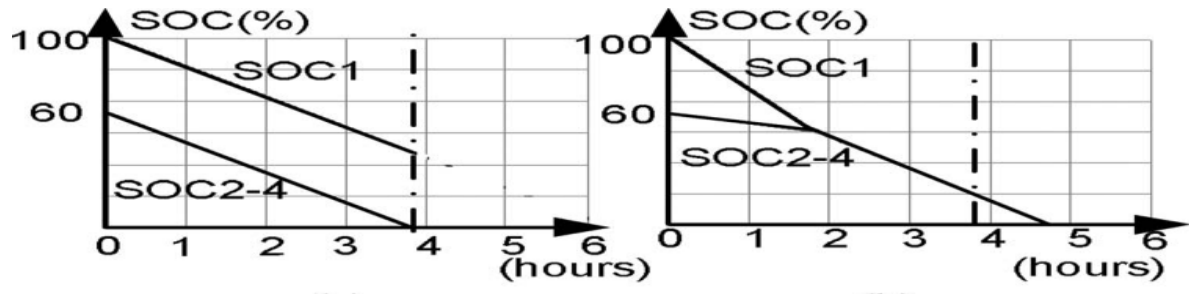

(a)

(b)

Fig. 10. SOC of all the batteries (a) with equal discharge current and (b) with their discharge current proportional to their SOCs. 


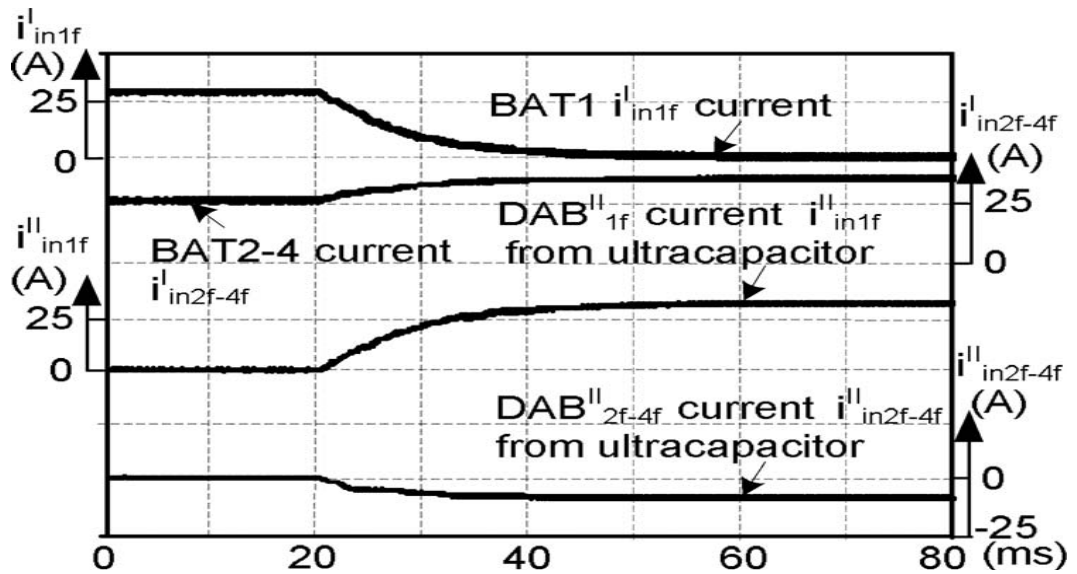

Fig. 11. Dynamic response of converter currents when one battery currentreference is made zero (Case II).

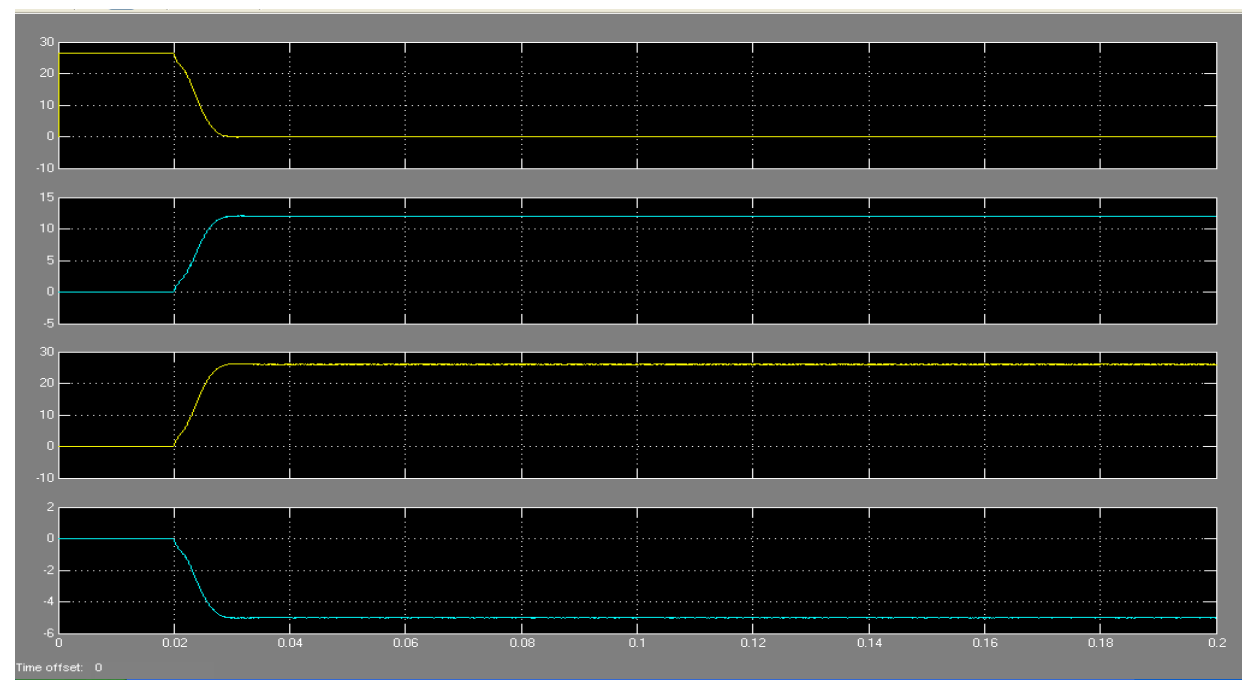

Fig. 11.. Output simulation result of Dynamic response of converter currents when one battery current reference is made zero (Case II).

plained the needs for SOC control and propose control methodsfor SOC balancing of the battery units. emphasizedon power sharing among different batteries dependingon their charge level and to achieve this, droop coefficient isadjusted to be inversely proportional to their charge level. One extreme case can be a situation when one of the battery currenthas to be made zero to disconnect it for replacement. Fig. 11shows the simulation results corresponding to this dynamics. The current reference to the DAB connected to the battery tobe replaced is slowly made zero starting at $t=20 \mathrm{~ms}$. The reductionof this battery power is compensated by other batteriesby increasing their current references. The voltage controllers

adjust the current references of the DABs connected to the ultracapacitorto regulate $\operatorname{Vo}(1-4)$ at the reference value. Fig. 11shows the dynamic response of the average converter input currentsfor letting one battery current iIin $1 \mathrm{f}$ to become zero. Theaverage currents $\operatorname{ilin}(2 \mathrm{f}-4 \mathrm{f})$ of converters connected to other batteriesslowly increase to compensate. Because of this change inbattery currents, the input current iIlin $1 \mathrm{f}$ of DABII1 increases and input currents iIIin( $2 \mathrm{f}-4 \mathrm{f})$ of DABII2-4 decrease to regulate the dcbus.

\section{Case III: State of Charge Control of Ultracapacitor}

The ultracapacitor SOC control is also an important requirementof the energy management scheme. The ultracapacitorSOC can be easily estimated from its terminal voltage. Theenergy management scheme has to maintain the ultracapacitorSOC within a band. If the ultracapacitor voltage falls below thelower band, then the energy management scheme generates appropriatecurrent references for the battery and ultracapacitor. 


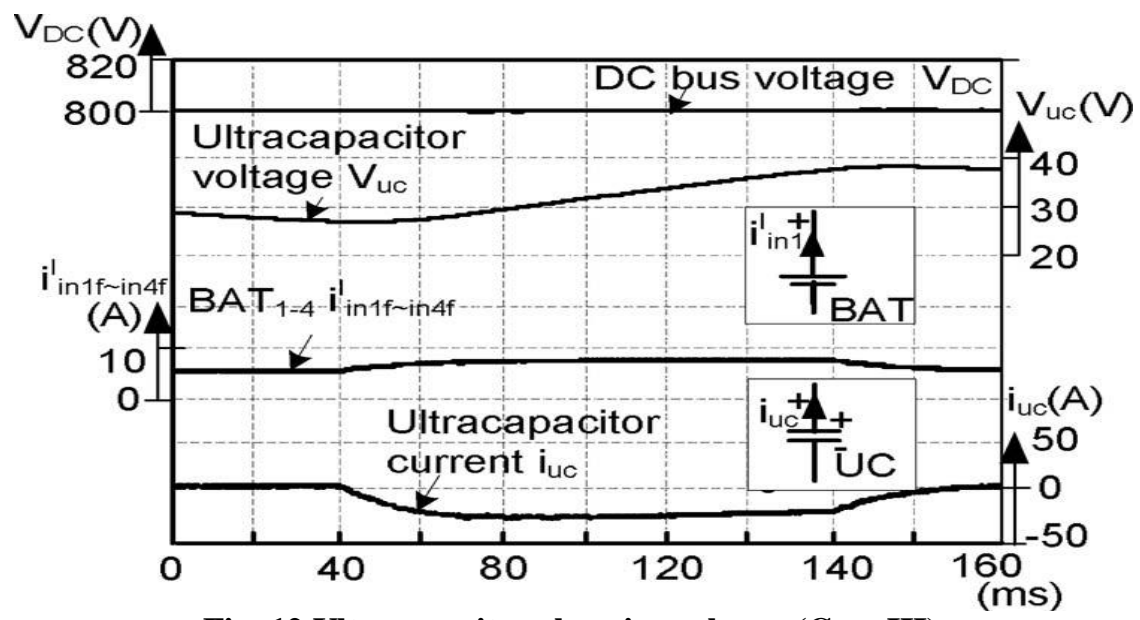

Fig. 12.Ultracapacitor charging scheme (Case III).

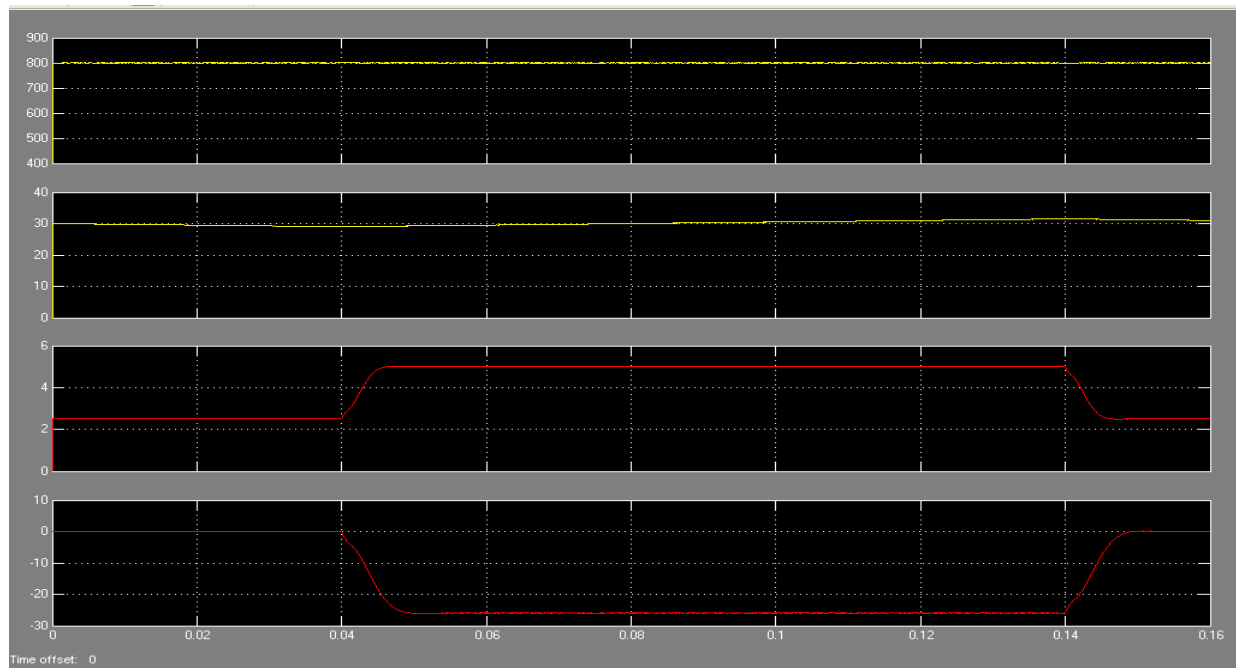

Fig. 12.Output simulation result of Ultracapacitor charging scheme (Case III).

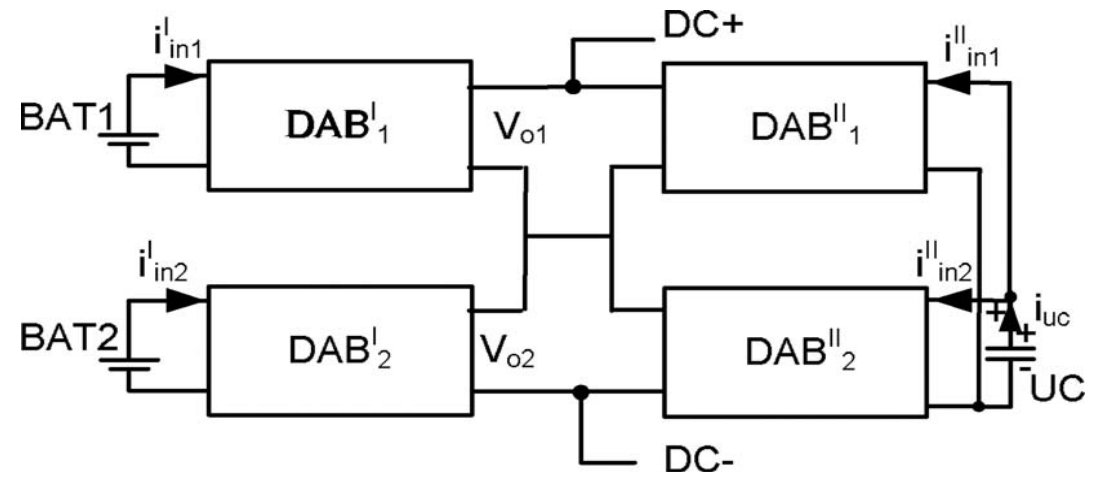

Fig. 13. Block diagram of the experimental setup.

The simulation results showing ultracapacitor charging processis presented in Fig. 12. For charging the ultracapacitor, a negativecurrent reference is added to the controllers of the DABsinterfacing it to the dc bus. Hence, the ultracapacitor currentbecomes negative, as shown in Fig. 12. To compensate for thisoutflow of current from the dc bus, a positive current referenceis added to the controllers of the DABs interfacing the batteriesto the dc bus. The resulting increase in magnitude of averagebattery currents ilin $(1 \mathrm{f}-4 \mathrm{f})$ is shown in Fig. 12. Once the ultracapacitorgets charged, i.e., the ultracapacitor voltage VUCreaches the upper band, this added offset current is removed.Fig. 12 shows that there is no disturbance in the dc-bus voltageVdcthroughout this process. 


\section{CONCLUSION}

ThisCESS interfaces battery as a high energy density storage, andultracapacitor as a high power density storage to the dc bus.The dc-dc converter structure is formed using DAB moduleswhose terminals are connected in series or parallel dependingon feasibility. The proposed modular dc-dc converter topologyalong with its energy management scheme can flexibly share the power between different batteries and ultracapacitor. Thescheme is validated based on fuzzy logic controller simulation in thispaper.

\section{REFERENCES}

\section{Proceedings Papers:}

[1] A. E. Curtright and J. Apt, "The character of power output from utilityscalephotovoltaic systems," IProg. Photovolt: Res. Appl., vol. 16, pp. 241-247, 2008.

[2] T. Christen and M. Carlen, "Theory of ragone plots," J. Power Sources,vol. 91, no. 2, pp. 210-16, 2000.

[3] M. Glavin, P. Chan, S. Armstrong, and W. Hurley, "A stand-alone photovoltaicsupercapacitor battery hybrid energy storage system," in Proc.13th Power Electron. Motion Control Conf., 2008 (EPE-PEMC 2008),pp. 1688-1695.

[4] Z.Guoju, T. Xisheng, andQ. Zhiping, "Research on battery supercapacitorhybrid storage and its application inmicrogrid," in Proc. 2010 Asia-PacificPower Energy Eng. Conf. (APPEEC), pp. 1-4.

[5] R. Dougal, S. Liu, and R. White, "Power and life extension of batteryultracapacitorhybrids," IEEE Trans. Compon.Packag. Technol., vol. 25,no. 1, pp. 120-131, Mar. 2002.

[6] B. and P. , "Battery-ultracapacitor active parallel interfacewith indirect control of battery current," in Proc. Power Energy Conf.Illinois (PECI), 2010, pp. 12-19.

[7] G. Guidi, T. Undeland, and Y. Hori, “An optimized converter for batterysupercapacitorinterface," in Proc. IEEE Power Electron. Spec. Conf.(PESC 2007), pp. 2976-2981.

[8] W. Li and G. Joos, "A power electronic interface for a battery supercapacitorhybrid energy storage system for wind applications," in Proc. IEEEPower Electron. Spec. Conf. (PESC 2008), pp. 1762-1768.

[9] F. Garcia, A. Ferreira, and J. Pomilio, "Control strategy for batteryultracapacitorhybrid energy storage system," in Proc. 24th Annu.IEEEAppl. Power Electron. Conf. Expo. (APEC 2009), pp. 826-832.

[10] F. H. Khan and L. M. Tolbert, "Bi-directional power management andfault tolerant feature in a 5-kw multilevel dc-dc converter with modulararchitecture," IET Trans. Power Electron., vol. 2, pp. 595-604, 2009.

[11] L. Palma and P. N. Enjeti, "A modular fuel cell, modular dc-dc converterconcept for high performance and enhanced reliability," IEEE Trans.Power Electron., vol. 24, no. 6, pp. 1437-1443, Jun. 2009.

[12] A. J. Watson, H. Dang, G. Mondal, J. C. Clare, and P. W. Wheeler, "Experimental implementation of a multilevel converter for power systemintegration,” in Proc. IEEE Energy Convers. Congr.Expo. (ECCE), Sep.2009, pp. 2232-2238.

[13] H. Zhou, T. Bhattacharya, and A. M. Khambadkone, "Composite energystorage system using dynamic energy management in microgrid applications,"in Proc. 2010 Int. Power Electron. Conf., Jun.,, pp. 1163-1168.

[14] S. Inoue and H. Akagi, "A bidirectional isolated dc-dc converter as a corecircuit of the next-generation medium-voltage power conversion system,"IEEE Trans. Power Electron., vol. 22, no. 2, pp. 535-542, Mar. 2007.

[15] H. Zhou and A. M. Khambadkone, "Hybrid modulation for dual-activebridgebidirectional converter with extended power range for ultracapacitorapplication," IEEE Trans. Ind. Appl., vol. 45, no. 4, pp. 1434-1442,Jul./Aug. 2009.

[16] R. W. A. A. D. Doncker, D. M. Divan, and M. H. Kheraluwala, "A threephasesoft-switched high-power-density dc/dc converter for high-powerapplications,” IEEE Trans. Ind. Appl., vol. 27, no. 1, pp. 63-73, Jan./Feb.1991.

[17] W. Chen, R. Xinbo, Y. Hong, and C. K. Tse, "Dc/dc conversion systemsconsisting of multiple converter modules: Stability, control, and experimentalverifications," IEEE Trans. Power Electron., vol. 24, no. 6,pp. 1463-1474, Jul./Aug. 2009.

[18] H. Zhou, A. M. Khambadkone, and X. Kong, "Fast dynamic response in afuel cell based converter using augmented energy storage," in Proc. IEEEPower Electron. Spec. Conf. (PESC 2007), Sep.,, pp. 1255-1260.

[19] L. Maharjan and E. A. S. Inoue, "State-of-charge (soc)-balancing controlof a battery energy storage system based on a cascade pwm converter,'IEEE Trans. Power Electron., vol. 24, no. 5, pp. 1628-1636, Jun. 2009.

[20] W. Du, X. Huang, S. Yang, F. Zhang, X. Wu, and Z. Qian, “A novelequalizationmethod with defective-battery-replacing for seriesconnectedlithium battery strings," in Proc. IEEE Energy Convers. Congr.Expo.(ECCE 2009), pp. 1808-1811.

[21] J. Guerrero, J. Vasquez, J. Matas, M. Castilla, and L. de Vicuna, "Controlstrategy for flexible microgrid based on parallel lineinteractive upssystems,” IEEE Trans. Ind. Electron., vol. 56, no. 3, pp. 726-736, Mar.2009.

[22] D. Tran, H. Zhou, and A. M. Khambadkone, "Energy management anddynamic control in composite energy storage system for micro-grid applications,"in Proc. IEEE Ind. Electr. (IECON-2010), pp. 1818-1824. 